\title{
Ultrasonic Assisted Turning of Al alloys: Influence of Material Processing to Improve Surface Roughness
}

\author{
Hélder Puga ${ }^{1, * \mathbb{C}}$, José Grilo ${ }^{1}$ and Vitor H. Carneiro ${ }^{2}$ \\ 1 CMEMS - UMinho, University of Minho, Campus of Azurém, 4800-058 Guimarães, Portugal; \\ jl.coelho.grilo@gmail.com \\ 2 MEtRiCS - Mechanical Engineering and Resource Sustainability, University of Minho, Campus of Azurém, \\ 4800-058 Guimarães, Portugal; d6705@dem.uminho.pt \\ * Correspondence: puga@dem.uminho.pt; Tel.: +351-253-510-220
}

Received: 21 March 2019; Accepted: 18 April 2019; Published: 19 April 2019

\begin{abstract}
Ultrasonic machining has been used over a decade to enhance the surface finishing and overall processing characteristics of conventional technologies. The benefits that are usually associated to this approach generate an increasing interest in both academic and industrial fields, especially in the turning operation due to its simple application. In this study, ultrasonic assisted turning is used to study the effect of intermittent tool contact on the surface quality of cast and wrought aluminium alloys. The resulting surface roughness and topography plots were evaluated through a three-dimensional (3D) optical profilometer. Additionally, stereo microscopy and detailed by scanning electron microscopy analyzed chip shape and morphology. The experimental results show that the appropriate use of an ultrasonic intermittent tool can improve the superficial quality up to $82 \%$ and reduce the maximum peak height by $59 \%$ for a $0.045 \mathrm{~mm} / \mathrm{rev}$ feed rate. When the feed rate is increased to $0.18 \mathrm{~mm} / \mathrm{rev}$, the surface roughness may be enhanced by $60 \%$ and the maximum peak height reduced by $76 \%$. Furthermore, due to the introduction of a distinct cutting mechanism, the traditional chip shape is modified when the ultrasonic tool excitation is applied. A model is suggested to explain the chip growth and the fracture behaviour.
\end{abstract}

Keywords: ultrasonic assisted turning; surface roughness; topography; chip morphology

\section{Introduction}

Ultrasonic technology, as a way of assisting manufacturing processes, has been used for over a decade [1]. The first implementation, denominated ultrasonic machining (USM), worked on a similar basis to abrasive water-jet machining. The abrasive slurry was fed to one end of the ultrasonic tool [2] and, through displacement amplifications using a sonotrode, the tool would machine profiles while the flowing fluid cleans any particles that are released from the operation [3].

The applicability of this technology has expanded to other processes due to the current evolution of this technique (e.g. turning, milling, drilling, forming, and others [4-8]). Overall, ultrasonic assisted machining (UAM) can be characterized as the superimposition of ultrasonic vibration onto a conventional tool that is used in machining processes [9]. Additionally, the motion is directly applied to the cutting tip or workpiece [10-12].

In UAM technologies, particularly in the case of turning, the cutting process becomes an intermittent procedure that separates the tool insert from the workpiece through micro-scaled high-frequency vibration. This, in turn, helps to dissipate the heat generated in the cutting process. When compared to conventional turning, UAT generates a more stable process, resulting in lower reaction loads, tool wear, and an enhanced surface finish of the workpiece $[13,14]$. 
An inconvenient restriction in surface finishing, as a consequence of equipment vibration, characterizes the conventional turning (CT) cutting process. This also has negative effects on the accuracy of cutting, disturbs the workpiece finishing, decreases the metal cutting rate, and reduces tool lifetime. Soleimanimehr et al. [15] reported that UAT reduced $35 \%$ of the diametrical error in the workpiece. When the appropriate frequency is used, the users can benefit from the use of UAT [16], especially in terms of surface quality [17] and tool wear reduction [18,19]. Additionally, ultrasonic assisted turning (UAT) is particularly useful when the material properties (e.g. ductility, high tensile strength, micro-hardness, grain orientation, etc.) may change the overall machinability [20].

The current study presents an approach of applying ultrasonic vibration during the turning of $\mathrm{Al}$ alloys, thus, generating the UAT process. The particular innovation of this process is the implementation of a resonant frequency tracking system that allows for a direct adaptation to stiffness changes in the system. Thus, the cutting process remains in optimized resonant conditions and prevents the operation in non-resonant states.

This work studies the influence of feed rate in the overall surface quality and roughness when the conventional tool is excited in the described conditions. Additionally, the influence of material properties, such as yield strength, toughness, and overall deformation mechanisms, are correlated with the overall chip formation mechanism that UAT promotes.

\section{Materials and Methods}

\subsection{Experimental Description}

The turning experiments (Figure 1a) were performed in dry condition while using a conventional lathe (EFI DU25, EFI, Trofa, Portugal). The Al alloy workpieces are given an anticlockwise rotation, while the tool vibration with UAT is aligned with the cutting direction (Figure 1 b). The lower side of the insert is used as the active cutting edge, which safely projects the resulting chip away from the user. Figure 1a shows the experimental setup and it identifies each component as the following: (1) Insert, (2) Workpiece, (3) Acoustic radiator (horn), (4) Transducer, (5) Support of UAT system, and (6) Spindle. MPInterconsulting manufactures the ultrasonic components (Le Locle, Switzerland).
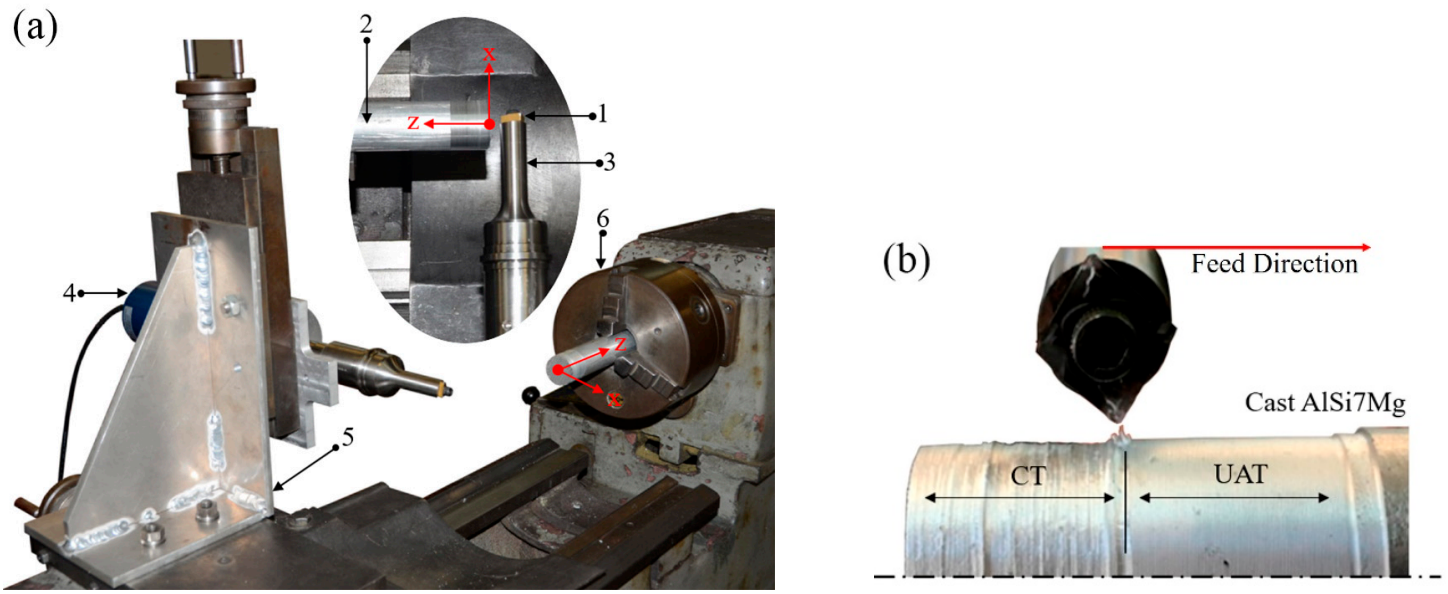

Figure 1. (a) Experimental setup. (b) Cutting contact during turning process.

\subsection{Specification of the Machining Process}

The tool insert was selected for the finishing and roughing operations at medium depths of cut and feed rates. The interrupted cuts at high metal removal rates and the type of material (Al alloys) were also considered in the insert selection. A Micrograin Cemented Carbide CVD-coated insert (reference CCMT120408PM, Sandvik, Stockholm, Sweden), with a $0.8 \mathrm{~mm}$ radius and $80^{\circ}$ nose angle, was selected to perform the turning experiments. 
According to Figure 1a, the tool insert (1) is directly attached to the horn (3) through a bolt, which, in turn, is fixed to the transducer (4). The piezoelectric transducer (electrical power up to $3000 \mathrm{~W}$ in continuous current) is powered by an ultrasonic generator that is based on the MMM (Multi-Mode,-Frequency,-Modulated) Technology. This component can produce high efficiency active power in wide-band sonic and ultrasonic vibrations. The ultrasonic generator supplies the required frequency in the range of $19-21 \mathrm{KHz}$, which generates an average amplitude of $20 \mu \mathrm{m}$ for the present configuration. The ultrasonic equipment is clamped in the booster nodal point and is bolted to an aluminium structure, which is itself fixed to the lathe (Figure 1a). Thus, all the movements of turning can be obtained with the same precision as that achieved by the base conventional lathe composition of equipment.

For comparison purposes, distinct $\mathrm{Al}$ alloys were selected to determine the behaviour of UAT under different grain morphology, hardness, yield strength, and toughness (i.e. ability to maintain plastic deformation in the chip). These properties were analysed to determine their impact in the overall surface roughness of UAT and conventional cutting processes. As such, as-cast Al7Si0.3Mg (7.44\% Si, $0.3 \% \mathrm{Mg}, 0.13 \% \mathrm{Fe}, 0.11 \% \mathrm{Ti}, 0.07 \% \mathrm{Cu}, 0.07 \% \mathrm{Mn}, 0.05 \% \mathrm{Zn}, 0.12 \%$ Res., Balance $\mathrm{Al}$ ) and wrought AA7050 $(5.74 \% \mathrm{Zn}, 2.11 \% \mathrm{Cu}, 1.98 \% \mathrm{Mg}, 0.12 \% \mathrm{Fe}, 0.09 \% \mathrm{Zr}, 0.05 \% \mathrm{Si}, 0.04 \% \mathrm{Mn}, 0.06 \%$ Res., Balance Al) alloys were the workpiece materials used. In addition to these individual materials, the work was carried out under different values of machining feed rates, as seen in Table 1 . The conventional cut is performed with the same set-up, only without ultrasonic vibration. The first 20 $\mathrm{mm}$ length of each sample are machined through conventional turning process, leaving the remaining $20 \mathrm{~mm}$ to be cut by the UAT that is superimposed in the tool, as shown in Figure 1b. The selected parameters and their values were defined by the experience of the authors and selected as the most suitable for performing this study.

Table 1. Experimental parameters.

\begin{tabular}{cc}
\hline Specification & Value \\
\hline Rotation per minute, $\mathrm{N}(\mathrm{rpm})$ & 760 \\
Depth of cut, $\mathrm{a}_{\mathrm{p}}(\mathrm{mm})$ & 0.5 \\
Cutting speed, $\mathrm{V}(\mathrm{m} / \mathrm{min})$ & 60 \\
Feed rate, $\mathrm{f}_{\mathrm{a}}(\mathrm{mm} / \mathrm{rev})$ & $0.045 ; 0.18$ \\
\hline
\end{tabular}

The referred methodology was performed in three distinct samples for each tested material, feed rate, and tool-excitation combination (a total of 32 samples). To avoid any inherent uncertainty issues, half of the samples were machined with a UAT-CT order, while the other half were machined with a CT-UAT order (i.e. the process was inverted). A new insert was used for every test to eliminate any wear related uncertainty.

\subsection{Post-Experimental Surface Characterization}

Posteriorly to the turning process, analysis was carried out using a three-dimensional (3D) optical profilometer (S-neox, Sensofar, Barcelona, Spain). The vertical scanning interferometry (VSI) mode characterized the machined surfaces for the CT and UAT samples on both alloys. This allows a nanometer resolution in the vertical axis. The magnification (DI, 10x) enables the measuring of 1.75 $\mathrm{mm} \times 1.32 \mathrm{~mm}(1360 \times 1024$ pixels $)$ areas with a lateral resolution of about $0.7 \mu \mathrm{m}$ for white light. Concerning the evaluation of surface quality, an arithmetic average was used as the common ground between samples, which is expressed through the surface roughness (Ra) value from the Equation (1). As defined in ISO $4287, l$ is the sample's tested length and $Z$ is the height of the profile at a determined coordinate (x). These values were monitored in a $1.75 \mathrm{~mm}$ straight line parallel to the sample turning axis using the 3D optical profilometer results, where three different observation fields were analyzed in 
each machined samples. The Maximum Peak Height of Profile $\left(R_{z}\right)$ was also determined while using the same data.

$$
R a=\frac{1}{l} \int_{0}^{l}|Z(x)| d x
$$

The morphology of the resulting chip formed during machining process was observed under a stereo microscope that was coupled to an image acquisition system (EZ4 HD, Leica, Wetzlar, Germany). A detailed characterization of their surfaces was performed using a scanning electron microscope (SEM—S 4100 Hitachi, Tokyo, Japan).

\subsection{Sample Casting and Testing}

The Al7Si0.3Mg alloy was melted inside a crucible, where it was held on an isothermal state $\left(720 \pm 5^{\circ} \mathrm{C}, 15 \mathrm{~min}\right)$ for homogenization. The Al5Ti1B (0.2\%mass [21]) and Al10Sr (0.3\%mass [22]) master alloys were added to the melt to promote a chemical grain refinement and modification of eutectic Si. The isothermal state was kept for another $5 \mathrm{~min}$ to allow for a full dissolving of the master alloys, after which ultrasound degassed the melt [23] to release entrapped hydrogen. This also prevents the sedimentation of the refining particles $[24,25]$. Posteriorly, the melt was allowed to cool down $\left(700^{\circ} \mathrm{C}\right)$ and poured into pre-heated $\left(250 \pm 2{ }^{\circ} \mathrm{C}\right)$ cylindrical $(\varnothing 30 \pm 0.5 \times 70 \mathrm{~mm})$ steel molds. The wrought AA7050 alloy was obtained by a commercial rod (Ø30 h7), where a $70 \mathrm{~mm}$ length section was cut to obtain the final shape for the required turning experiment.

The tensile specimens were manufactured from the casted and wrought cylinders according ISO 6892. Five specimens for each alloy were tested on an INSTRON 8874 universal testing equipment (Instron, Norwood, Massachusetts, USA) on displacement control $(0.1 \mathrm{~mm} / \mathrm{s})$. The instant values of load and displacement were recorded using a load cell and strain gauge, being posteriorly converted to a stress-strain plot.

\section{Results and Discussion}

Figures 2 and 3 show the average surface roughness and maximum peak height of the CT and UAT samples. Overall, the experimental results suggest a reduction of $55 \%-82 \%$ in terms of surface roughness $\left(R_{a}\right)$ when applying UAT. It may be also observed that there is a $59 \%-76 \%$ reduction in Maximum Peak Height $\left(\mathrm{R}_{\mathrm{z}}\right)$.
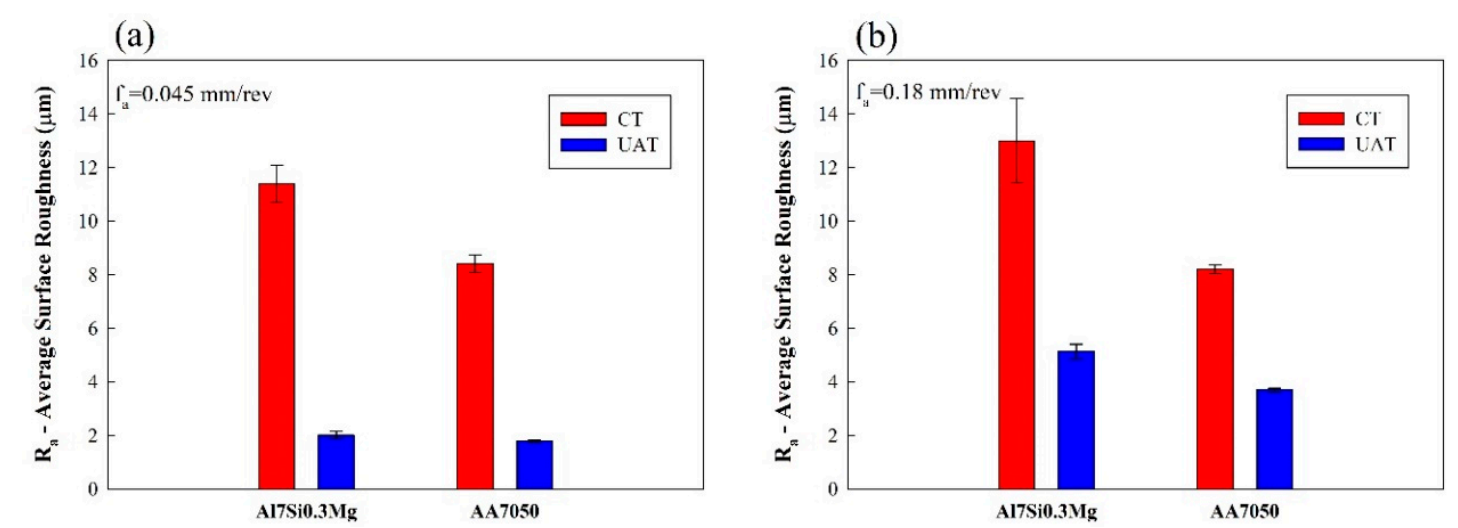

Figure 2. Average surface roughness $\left(\mathrm{R}_{\mathrm{a}}\right)$ for the tested materials using feed rate of (a) 0.045 and (b) $0.18 \mathrm{~mm} / \mathrm{rev}$. 
(a)

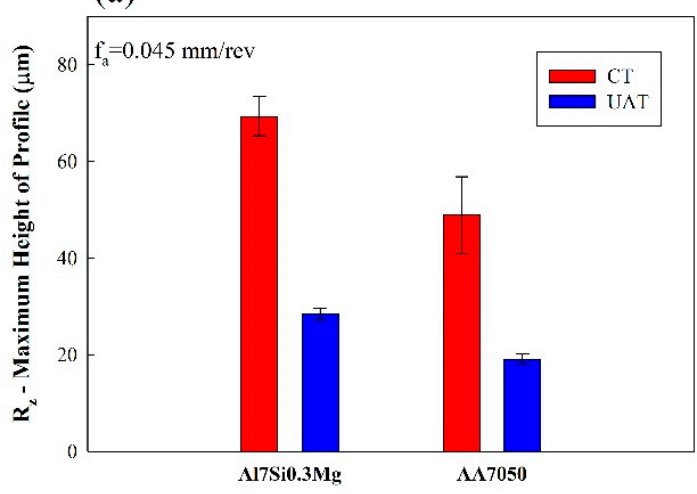

(b)

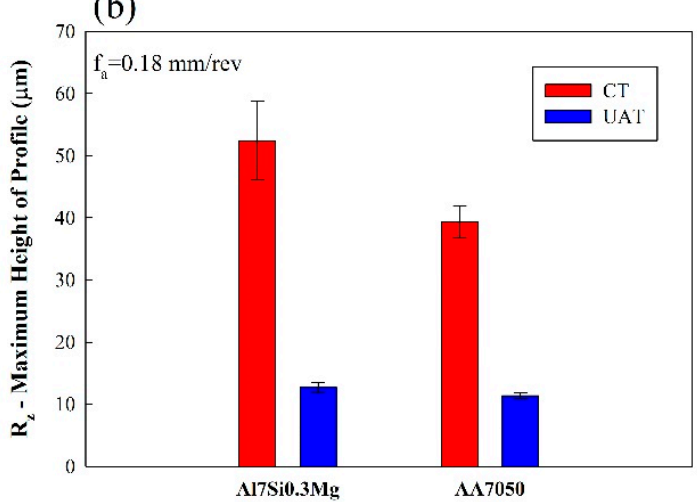

Figure 3. Maximum height of profile $\left(R_{z}\right)$ for the tested materials using feed rate of (a) 0.045 and (b) $0.18 \mathrm{~mm} / \mathrm{rev}$.

During the UAT cutting process, the resonance frequency that is driven by the generator was $20.470 \pm 0.005 \mathrm{kHz}$ and $20.205 \pm 0.005 \mathrm{kHz}$, respectively, for the feed rates of $0.18 \mathrm{~mm} / \mathrm{rev}$ and 0.045 $\mathrm{mm} / \mathrm{rev}$. As can be seen, during the ultrasonic assisted machining, the variation in feed rate promoted a shift in the resonant frequency value. Indeed, with the increasing of external loading as well as due to some incoherence on the base matrix, the resonant frequency of system varied by $265 \mathrm{~Hz}$ when the feed rate was increased from $0.045 \mathrm{~mm} / \mathrm{rev}$ to $0.18 \mathrm{~mm} / \mathrm{rev}$.

In fact, as stated by various authors $[10,20]$, a vibration cutting device can report different cutting behaviour when subjected to distinct conditions. Moreover, according to the same authors, the feed rate is suggested as the most influential parameter on surface quality. Gao and Sharma [26-28] showed that the depth of cut seems to have less effect on the surface roughness relative to the feed rate; however, it has been reported to generate higher cutting loads. Given the influence of the latter in the stiffness of the overall system, the depth of cut was kept constant to prevent the ultrasonic equipment to operate on non-resonant states. However, there may be still small stiffness changes in the system during the cutting process, which slightly change the system resonant frequency $(\sim 20 \mathrm{kHz})$, as stated by other published studies [29-31]. To correct this resonance shifting, a real-time a Phase Locked Loop (PLL) resonant frequency tracking system was implemented on the MMM generator (as patented by $\mathrm{M}$. Prokic [32]).

According to the results that are presented in Figures 2 and 3, it is clear that the base material has influence on the quality of machined surface. For the same operations conditions, the average of surface roughness $\left(\mathrm{R}_{\mathrm{a}}\right)$ and maximum peak height $\left(\mathrm{R}_{\mathrm{z}}\right)$ for the Al7Si0.3Mg cast alloy are higher than those that were evaluated for case of the AA7050 alloy. The quality of surfaces machined by UAT suggest a better homogeneity and repeatability (i.e. lower standard deviation values in Figures 2 and 3 ) when compared to conventional machining. Additionally, the introduction of ultrasonic tool-vibration may be useful in industrial applications in distinct approaches: (i) maintaining feed rate to obtain machined parts with enhanced surface quality; and, (ii) increase feed rate, while trying to maintain surface quality, to reduce the machining times.

The roughness mitigation and enhanced surface quality in UAT is more evident when a lower feed rate $\left(f_{a}=0.045 \mathrm{~mm} / \mathrm{rev}\right)$ is applied. To better understand the effect of the workpiece material, the resulting geometry was observed and studied using a 3D surface perfilometer. Figure 4 shows the topography of sample, as presented in Figures 2a and $3 a$. 


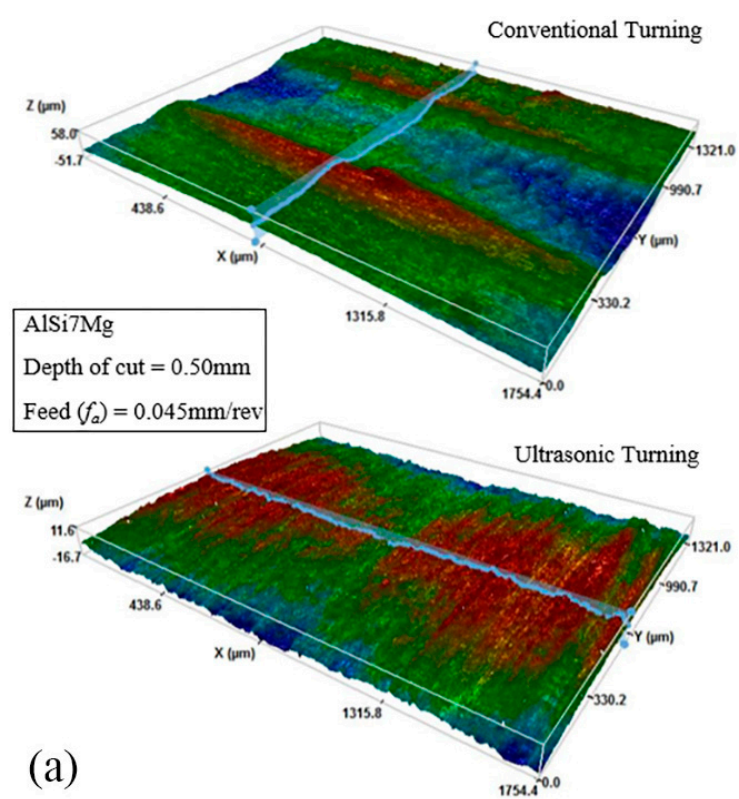

Figure 4. Surface topography $\left(\mathrm{f}_{\mathrm{a}}=0.045 \mathrm{~mm} / \mathrm{rev}\right)$ :

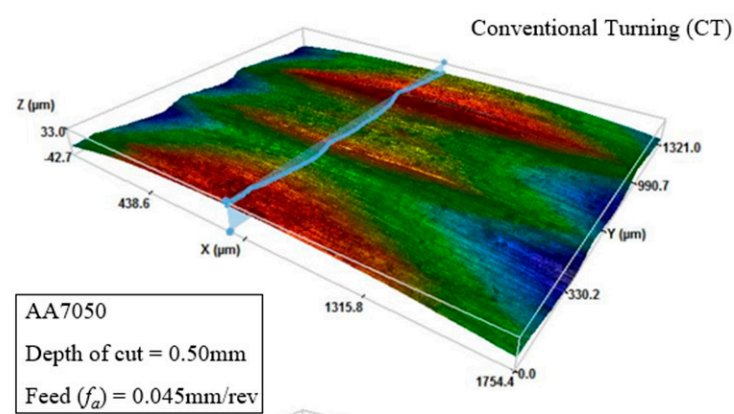

(b)

It may be observed that, while the rough cutting is evidently shown in the traditional process, there are almost no periodic peaks that can be traced upon using the ultrasonic vibration. These observations on surface plots are in accordance with other authors [33]. The AA7050 samples in Figure $4 \mathrm{~b}$ show a consistent tool path, particularly for the UAT, which resulted in the most homogenous texture of all the samples. In contrast, the conventional turning Al7Si0.3Mg samples displays damaged topography. The tool trajectory can be easily detected on the workpiece surface through the ridges that formed from its plastic deformation [34]. Although, such a detrimental effect is not seen when UAT is applied. This observation is in accordance with the different standard the deviation values for UAT that are presented in Figures 2a and 3a, suggesting a close relationship between the material deformation properties and the UAT performance.

Figure 5 displays the average stress-strain curves from the tensile tests. It is shown that the alloys display a distinct behaviour, allowing for the study of contrasting deformation mechanisms. However, given that they are both $\mathrm{Al}$ alloys, they are able to reduce other machining variables that could influence the results (e.g. friction coefficient, thermal conductivity and expansion, etc.). It may be observed that the Al7Si0.3Mg alloy displays a relatively prominent plastic domain. This fact is supported by its higher toughness $\left(T=1.21 \mathrm{MJ} / \mathrm{m}^{3}\right)$ when compared to the AA7050 alloy $\left(\mathrm{T}=0.77 \mathrm{MJ} / \mathrm{m}^{3}\right)$. Additionally, the AA7050 alloy displays fragile behaviour, being observed in the failure without localized necking and by the yield strength $\left(\sigma_{\mathrm{y}}\right)$ values being very close to its tensile strength $\left(\sigma_{\mathrm{UTS}}\right)$. Overall, the contrasting deformation mechanisms between the tested alloys generate different cutting and chip forming mechanisms for both the CT and UAT conditions. 


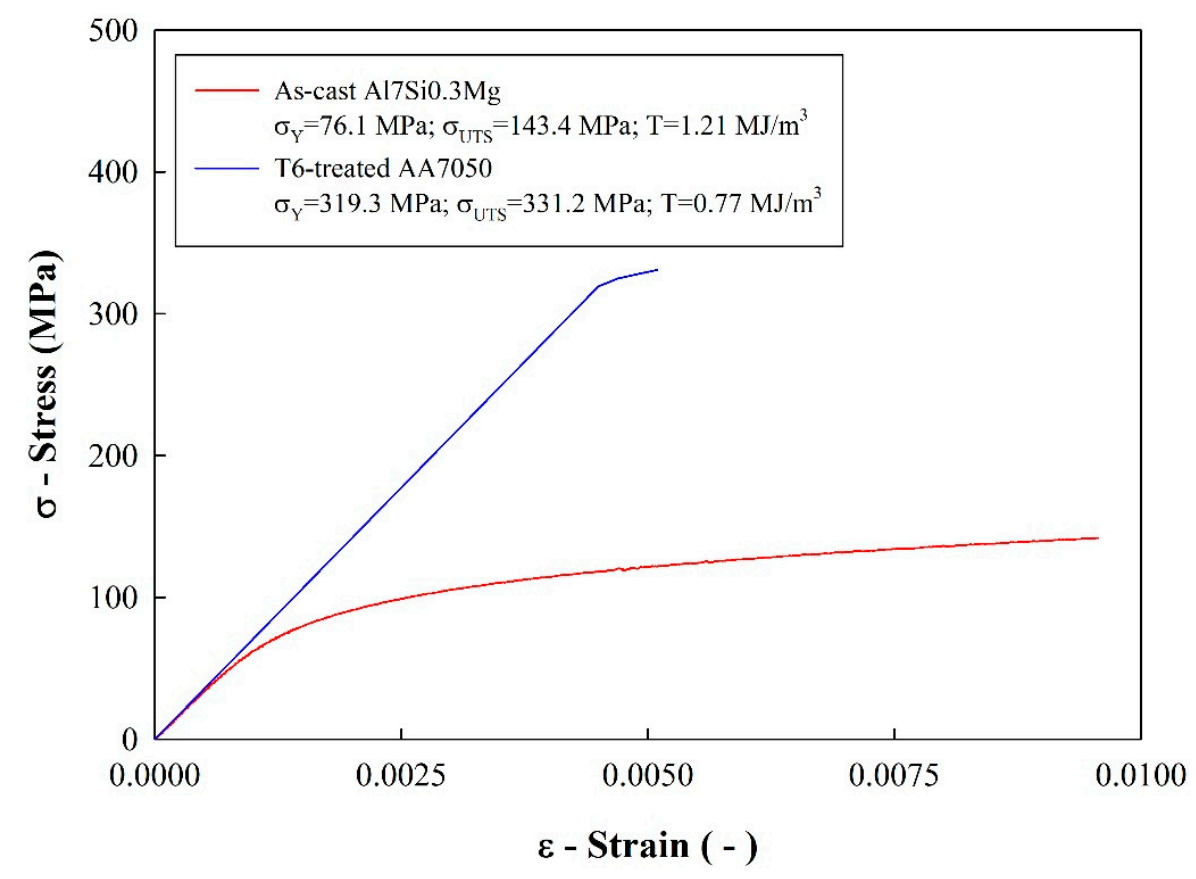

Figure 5. Average stress-strain curved of the tested materials (Al7Si0.3Mg and AA7050).

Chips were collected and analysed for a better understanding of the UAT cutting mechanism, (Figure 6) and these results were correlated with the properties that are displayed in Figure 5. According to the results, Figure 7 illustrates the cutting mechanism and the chip morphology that are based on the material and turning processes.
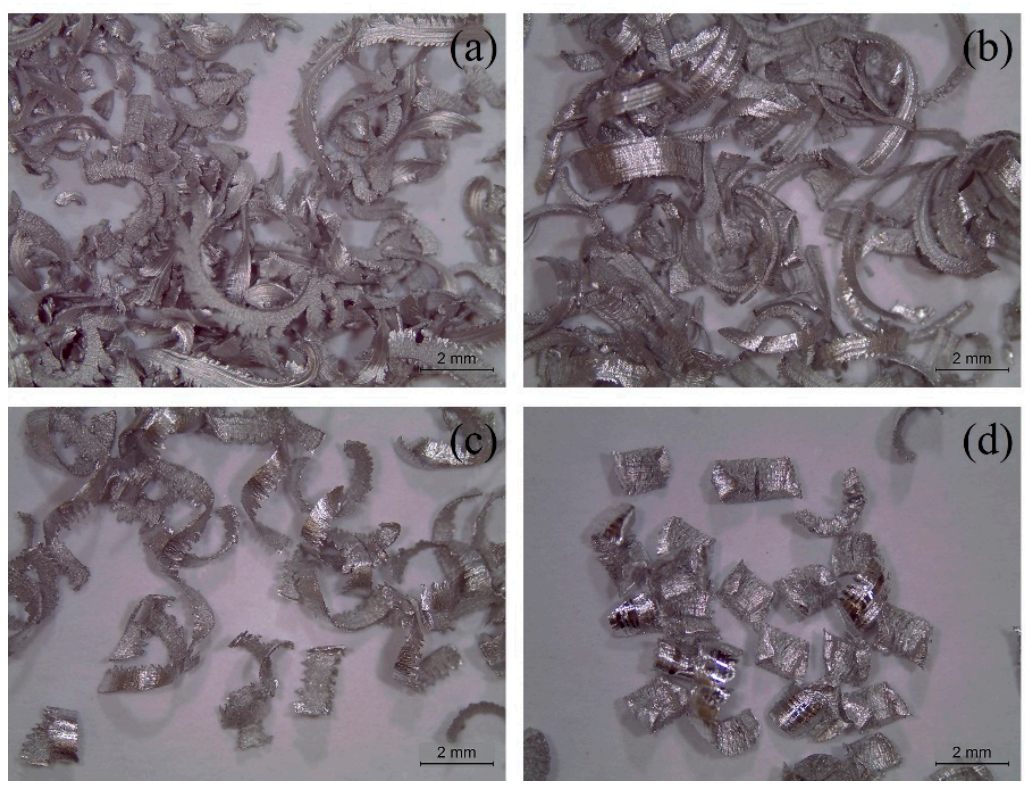

Figure 6. Example of stereo microscope ( $5 x$ magnification) images of chip morphology with $f_{a}=0.045$ $\mathrm{mm} / \mathrm{rev}$. Al7Si0.3Mg sample by (a) ultrasonic assisted turning (UAT) and (b) conventional turning (CT). AA7050 sample by (c) UAT and (d) CT. 

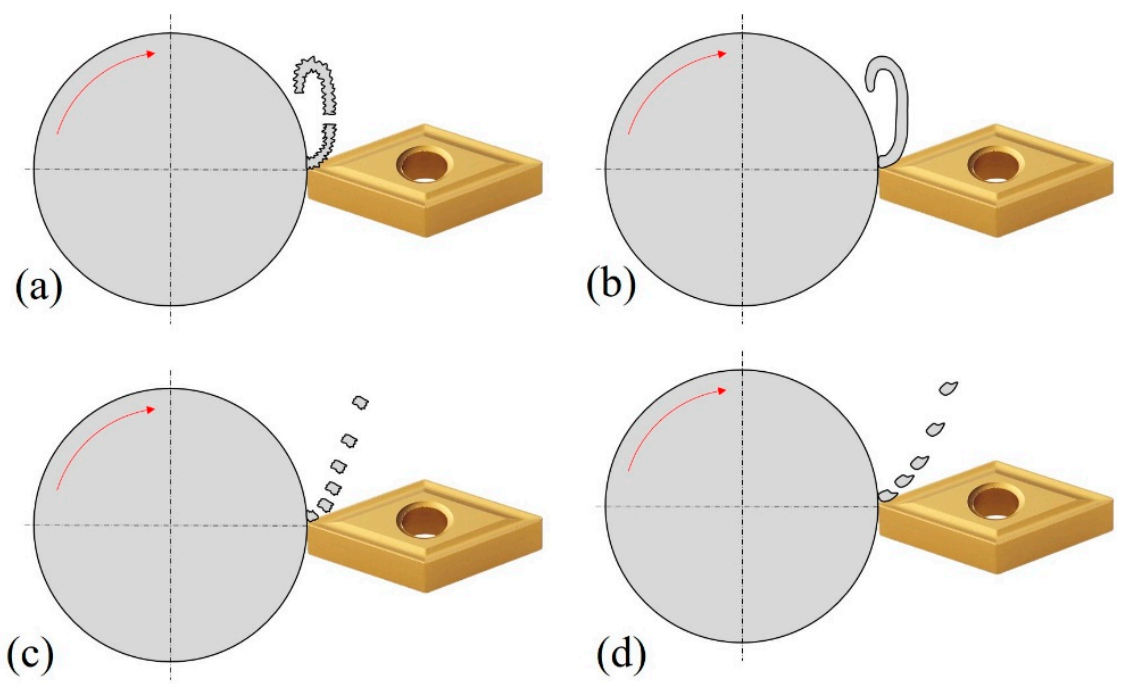

Figure 7. Suggested chip formation during the turning operation: Al7Si0.3Mg sample by (a) UAT and (b) CT; and, AA7050 sample by (c) UAT and (d) CT.

The chips from the same process share the similar traits. As depicted in Figure $6 \mathrm{~b}, \mathrm{~d}$, chips from traditional turning present themselves as slightly longer and thicker, followed with small side burr. As shown in Figure 7b, Al7Si0.3Mg produced semi-continuous chips, whereas AA7050 in Figure 6d generated a segmented non-homogenous chip. The latter distinguishes from other samples through its smaller radius curls and taller sawteeth. The UAT process, as exemplified in Figure $7 \mathrm{a}, \mathrm{c}$, shows larger chip curl radius. However, signs of violent tear taking place in its side burrs are found in Figure $6 \mathrm{a}, \mathrm{c}$, where Nath and Rahman made similar observations [35]. Analogous to the conventional turning, AA7050 chips that were produced by UAT are shorter in length. As shown in Figure $6 c, d$, the side burrs of the commercial alloy are more evenly distributed when compared to the casted specimen. The fact that the Al7Si0.3Mg alloy is more ductile than the AA7050 alloy allows for a more plastic deformation to be supported before the overall chip separation in the cast alloy. On the other hand, the wrought alloy is separated from the workpiece before severe material flow occurs.

When considering the nature of the cutting mechanism of UAT, violent rupture is to be expected as a result of its imposed vibration. Nevertheless, this does not contribute to worse results when compared with CT, as previously seen from the results in Figures 2 and 3. On traditional turning, the lamellar segregation is determined by the workpiece mechanical properties, especially the presence of plastic deformation. According to the magnifications in Figure 6, this is supported by the plastic deformation and toughness of the Al7Si0.3Mg cast alloy. However, with ultrasonic vibration, chip morphology implies that the tool's motion heavily influences its formation, which is in accordance to other published studies [36,37].

As seen from the topography in Figure 4 and the standard deviation in Figures 2 and 3, the casted alloy offers relative poor machinability when compared with the wrought alloy while using the same process. This may be correlated with the tensile test results in Figure 5. It is shown that the latter chip formation is possible when there is an effective plastic domain (as-cast Al7Si0.3Mg), and absent where the alloy presents a fragile behaviour (wrought AA7050). This fact may be highlighted by the determined toughness values, in which the low toughness that characterizes the AA7050 alloy does not allow the referred chip forming effect. To better evaluate the surface of the chips, the SEM images from both cutting methods and alloys are analysed, as seen in Figure 8. 

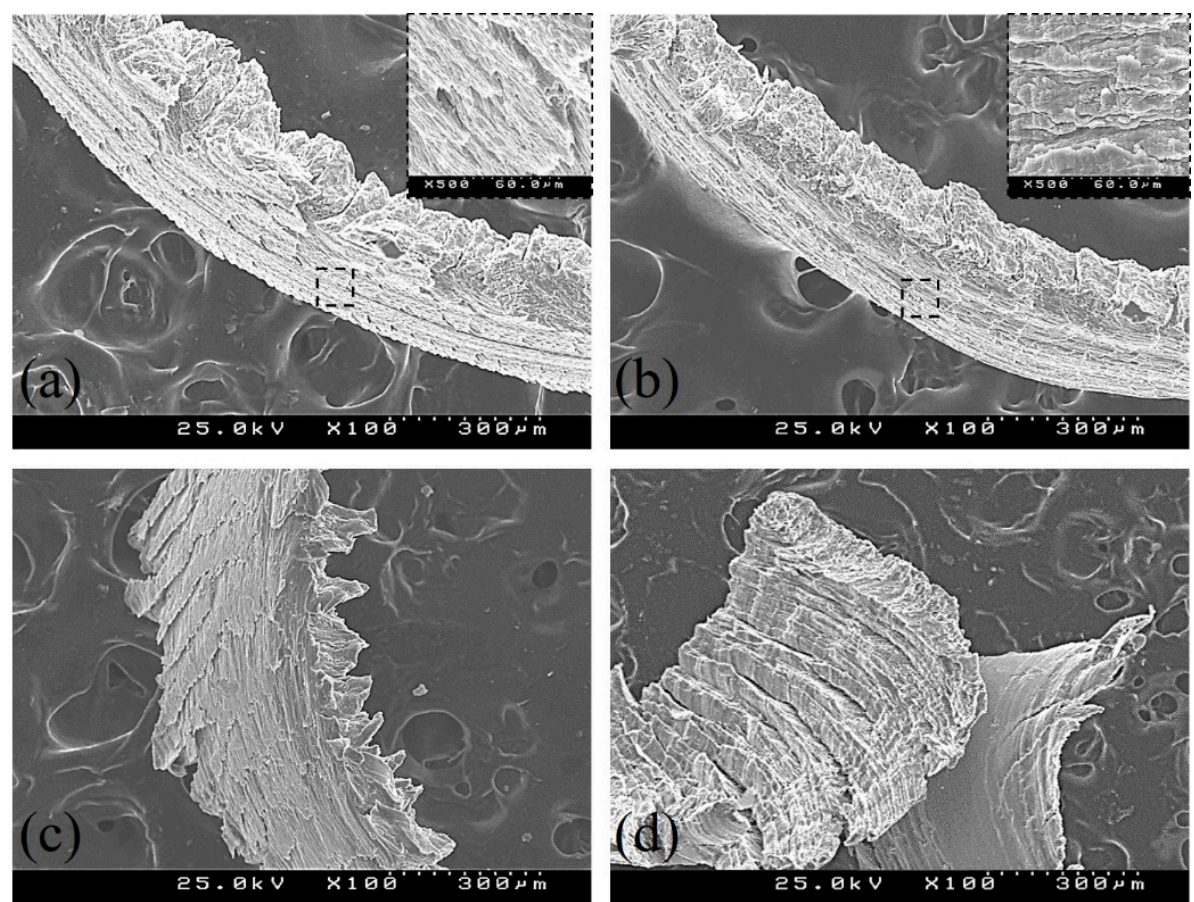

Figure 8. Scanning electron microscope (SEM) images of chip morphology with $\mathrm{f}_{\mathrm{a}}=0.045 \mathrm{~mm} / \mathrm{rev}$. Al7Si0.3Mg sample by (a) UAT and (b) CT. AA7050 sample by (c) UAT and (d) CT.

Despite the casted chip share similar curvature shown in Figure 8a,b, they differ in the texture that originated from the tool-chip contact. While conventional turning shows signs of friction and adhesion in the secondary deformation zone, UAT surface is differentiated by its roughness consistency and orientation. The extruded alloy (AA7075) that was subjected to UAT is characterized by the scaled pattern shown in Figure 8c. Such a feature can attributed to the intermittent contact of the process and lower toughness (Figure 5). This combination results in the generation of small superficial cracks in secondary deformation area until the chip fractures. In contrast, chips from the same alloy that are machined by CT (Figure 8d) have a partially smoother surface. It is proposed that a lower tool-chip contact area induced by the curvature of these chips favoured these unaffected sections.

\section{Conclusions}

In the present study, an experimental approach was employed to compare conventional (CT) and ultrasonic assisted turning (UAT). Overall, the quantification of surface roughness and the resultant chips analyse the benefit of introducing an ultrasonic excitation on the tool to machine $\mathrm{Al}$ alloys.

The experimental results showed that the application and ideal use of the ultrasonic elements and the surface quality of machining samples are improved up to $56 \%$ and are characterized by uniformly distributed topography. It is shown that this benefit is more noticeable in materials with lower plasticity, especially when the feed rate is increased. This may be justified by the production of a shorter chip and the presence of a uniform deformed morphology.

UAT is shown to be beneficial in terms of surface quality when considering the manufacturing differences between the casted and commercial extruded alloys. The adopted method is presented as an accessible approach to obtain surface quality when machining $\mathrm{Al}$ alloys while considering the conditions in which they were tested and the obtained results.

Author Contributions: Conceptualization, H.P. and J.G.; methodology, J.G. and H.P.; validation, H.P., J.G. and V.H.C.; formal analysis, H.P. and V.H.C.; resources, H.P.; data curation, H.P., J.G. and V.H.C.; writing-original draft preparation, H.P., J.G. and V.H.C. 
Acknowledgments: This study was supported by FEDER/COMPETE funds and by national funds through FCT and was developed on the aim of the research Post-Doctoral grant SFRH/BPD/76680/2011. Additionally, this work is supported by FCT with the reference project UID/EEA/04436/2019.

Conflicts of Interest: The authors declare no conflict of interest.

\section{References}

1. Brehl, D.E.; Dow, T.A. Review of vibration-assisted machining. Precis. Eng. 2008, 32, 153-172. [CrossRef]

2. He, J.F.; Guo, Z.N.; Lian, H.S.; Liu, J.W.; Yao, Z.; Deng, Y. Experiments and simulations of micro-hole manufacturing by electrophoresis-assisted micro-ultrasonic machining. J. Manuf. Process. Technol. 2019, 264, 10-20. [CrossRef]

3. Kumar, J. Ultrasonic machining-A comprehensive review. Mach. Sci. Technol. 2013, 17, 325-379. [CrossRef]

4. Chen, G.; Ren, C.; Zou, Y.; Qin, X.; Lu, L.; Li, S. Mechanism for material removal in ultrasonic vibration helical milling of Ti 6Al 4V alloy. Int. J. Mach. Tools Manuf. 2019, 138, 1-13. [CrossRef]

5. Zhao, C.; Wang, X.; Zhao, B.; Jiao, F. Microstructure of High-Performance Aluminum Alloy Surface Processed by the Single-Excitation Same-Frequency Longitudinal-Torsional Coupled Ultrasonic Vibration Milling. Materials 2018, 11, 1975. [CrossRef] [PubMed]

6. Sedaghat, H.; Xu, W.; Zhang, L. Ultrasonic vibration-assisted metal forming: Constitutive modelling of acoustoplasticity and applications. J. Mater. Process. Technol. 2019, 265, 122-129. [CrossRef]

7. Molaie, M.; Zahedi, A.; Akbari, J. Effect of Water-Based Nanolubricants in Ultrasonic Vibration Assisted Grinding. J. Manuf. Mater. Process. 2018, 2, 80. [CrossRef]

8. Puga, H.; Grilo, J.; Oliveira, F.J.; Silva, R.F.; Girão, A.V. Influence of external loading on the resonant frequency shift of ultrasonic assisted turning: Numerical and experimental analysis. Int. J. Adv. Manuf. Technol. 2018, 101, 2487-2496. [CrossRef]

9. Iorio, E.D.; Bertolini, R.; Bruschi, S.; Ghiotti, A. Design and development of an ultrasonic vibration assisted turning system for machining bioabsorbable magnesium alloys. Procedia CIRP 2018, 77, 324-327. [CrossRef]

10. Cakir, F.H.; Gurgen, S.; Sofuoglu, M.A.; Celik, O.N.; Kushan, M.C. Finite Element Modeling of Ultrasonic Assisted Turning of Ti6Al4V Alloy. Procedia Soc. Behav. Sci. 2015, 195, 2839-2848. [CrossRef]

11. Mehbudi, P.; Baghlani, V.; Akbari, J.; Bushroa, A.R.; Mardi, N.A. Applying Ultrasonic Vibration to Decrease Drilling-Induced Delamination in GFRP Laminates. Procedia CIRP 2013, 6, 577-582. [CrossRef]

12. Tao, G.; Zhang, J.; Shen, X.; Bai, L.; Ma, C.; Wang, J. Feasibility Study on Ultrasonic Vibration Assisted Milling for Squamous Surface. Procedia CIRP 2016, 42, 847-852. [CrossRef]

13. Brehl, D.E.; Dow, T.A. Review of Vibration-Assisted Machining Methods for Precision Fabrication; North Carolina State University Raleigh: Raleigh, NC, USA, 2006.

14. Sharma, V.; Pandey, P.M. Optimization of machining and vibration parameters for residual stresses minimization in ultrasonic assisted turning of 4340 hardened steel. Ultrasonics 2016, 70, 172-182. [CrossRef] [PubMed]

15. Soleimanimehr, H.; Nategh, M.J.; Najafabadi, A.F.; Zarnani, A. The analysis of the Timoshenko transverse vibrations of workpiece in the ultrasonic vibration-assisted turning process and investigation of the machining error caused by this vibration. Precis. Eng. 2018, 54, 99-106. [CrossRef]

16. Farahnakian, M.; Razfar, M.R.; Biglari, F.R. Multi-constrained optimization in ultrasonic-assisted turning of hardened steel by electromagnetism-like algorithm. Proc. Inst. Mech. Eng. Part B J. Eng. Manuf. 2015, 229, 1933-1944. [CrossRef]

17. Liu, X.; Zhang, J.; Hu, X.; Wu, D. Influence of tool material and geometry on micro-textured surface in radial ultrasonic vibration-assisted turning. Int. J. Mech. Sci. 2019, 152, 545-557. [CrossRef]

18. Lofti, M.; Amini, S.; Aghaei, M. Tool wear modeling in rotary turning modified by ultrasonic vibration. Simul. Model. Pract. Theory 2018, 87, 226-238.

19. Lofti, M.; Amini, S.; Aghaei, M. 3D FEM simulation of tool wear in ultrasonic assisted rotary turning. Ultrasonics 2018, 88, 106-114.

20. Xu, W.-X.; Zhang, L.-C. Ultrasonic vibration-assisted machining: Principle, design and application. Adv. Manuf. 2015, 3, 173-192. [CrossRef]

21. Guan, R.-G.; Tie, D. A Review on Grain Refinement of Aluminum Alloys: Progresses, Challenges and Prospects. Acta Metall. Sin. Engl. Lett. 2017, 30, 409-432. [CrossRef] 
22. Ebhota, W.S.; Jen, T.-C. Effects of Modification Techniques on Mechanical Properties of Al-Si Cast Alloys. In Aluminium Alloys-Recent Trends in Processing, Characterization, Mechanical Behavior and Applications; Sivasankaran, S., Ed.; InTech: London, UK, 2017; ISBN 978-953-51-3697-2.

23. Barbosa, J.; Puga, H. Ultrasonic melt processing in the low pressure investment casting of $\mathrm{Al}$ alloys. J. Mater. Process. Technol. 2017, 244, 150-156. [CrossRef]

24. Carneiro, V.H.; Puga, H.; Meireles, J. Heat treatment as a route to tailor the yield-damping properties in A356 alloys. Mater. Sci. Eng. A 2018, 729, 1-8. [CrossRef]

25. Tuan, N.Q.; Puga, H.; Barbosa, J.; Pinto, A.M.P. Grain refinement of Al-Mg-Sc alloy by ultrasonic treatment. Met. Mater. Int. 2015, 21, 72-78. [CrossRef]

26. Gao, G.F.; Zhao, B.; Liu, C.S. Research on the influence of the cutting conditions on the surface microstructure of ultra-thin wall parts in ultrasonic vibration cutting. J. Manuf. Process. Technol. 2002, 129, 66-70. [CrossRef]

27. Sharma, V.; Pandey, P.M. Recent advances in ultrasonic assisted turning: A step towards sustainability. Cogent Eng. 2016, 3, 1222776. [CrossRef]

28. Sharma, V.; Pandey, P.M. Experimental investigations and statistical modeling of surface roughness during ultrasonic-assisted turning with self-lubricating cutting inserts. Proc. Inst. Mech. Eng. Eng. 2018, 232, 709-722. [CrossRef]

29. Teimouri, R.; Amini, S.; Mohagheghian, N. Experimental study and empirical analysis on effect of ultrasonic vibration during rotary turning of aluminum 7075 aerospace alloy. J. Manuf. Process. 2017, 26, 1-12. [CrossRef]

30. Zhou, M.; Hu, L. Development of an innovative device for ultrasonic elliptical vibration cutting. Ultrasonics 2015, 60, 76-81. [CrossRef]

31. Zou, P.; Xu, Y.; He, Y.; Chen, M.; Wu, H. Experimental Investigation of Ultrasonic Vibration Assisted Turning of 304 Austenitic Stainless Steel. Shock Vib. 2015, 2015, 817598. [CrossRef]

32. Miodrag, P. Multifrequency Ultrasonic Structural Actuators. European Patent EP1238715A1, 11 September 2002.

33. Amini, S.; Teimouri, R. Parametric study and multicharacteristic optimization of rotary turning process assisted by longitudinal ultrasonic vibration. Proc. Inst. Mech. Eng. Part E J. Process Mech. Eng. 2017, 231, 978-991. [CrossRef]

34. Marinescu, I.D.; Rowe, W.B.; Dimitrov, B.; Ohmori, H. Introduction. In Tribology of Abrasive Machining Processes; Elsevier: Oxford, UK, 2013; pp. 3-12. ISBN 978-1-4377-3467-6.

35. Nath, C.; Rahman, M. Effect of machining parameters in ultrasonic vibration cutting. Int. J. Mach. Tools Manuf. 2008, 48, 965-974. [CrossRef]

36. Muhammad, R.; Hussain, M.S.; Maurotto, A.; Siemers, C.; Roy, A.; Silberschmidt, V.V. Analysis of a free machining $\alpha+\beta$ titanium alloy using conventional and ultrasonically assisted turning. J. Mater. Process. Technol. 2014, 214, 906-915. [CrossRef]

37. Sui, H.; Zhang, X.; Zhang, D.; Jiang, X.; Wu, R. Feasibility study of high-speed ultrasonic vibration cutting titanium alloy. J. Mater. Process. Technol. 2017, 247, 111-120. [CrossRef]

(C) 2019 by the authors. Licensee MDPI, Basel, Switzerland. This article is an open access article distributed under the terms and conditions of the Creative Commons Attribution (CC BY) license (http://creativecommons.org/licenses/by/4.0/). 